GEOUSP - Espaço e Tempo, São Paulo, No 28, pp. 105 - 124, 2010

\title{
A valorização de espaços de desindustrialização na metrópole: a produção do espaço como produção da segregação'
}

\author{
Rafael Faleiros de Padua*
}

\begin{abstract}
Resumo
Através do estudo do processo de desindustrialização e da reestruturação em curso de um fragmento da metrópole de São Paulo, a pesquisa busca compreender aspectos da reprodução da urbanização no momento atual. Este fragmento, situado ao norte do distrito de Santo Amaro, constitui-se a partir da grande industrialização das décadas de 1950/60/70, como uma área industrial e um local de moradia da classe operária. A indústria foi o principal indutor da urbanização do lugar, organizando a sua vida social, transformando-se em sua principal referência, produzindo uma vida cotidiana fragmentada. Verificamos, no entanto, que há um período relativamente curto de estabelecimento da indústria aí, pois já a partir do final da década de 1980 se verifica o início do declínio industrial no fragmento, processo que se intensifica na década de 1990 e se acentua ainda mais no momento atual. Com isso, há uma desintegração da vida social do fragmento decorrente da saída ou do fechamento de indústrias, já que bares fecham, espaços de moradias operárias são desocupadas e demolidas, muitos edifícios e terrenos industriais permanecem abandonados. Ao mesmo tempo, este espaço de desindustrialização, por ter uma localização privilegiada em relação a áreas já consolidadas como centralidades de negócios, passa a receber empreendimentos ligados às lógicas "modernas" do eixo empresarial sudoeste, promovendo uma transformação radical das espacialidades e aprofundando a fragmentação da vida cotidiana e a segregação sóaio-espacial.
\end{abstract}

Palavras-chave: industrialização, urbanização, desindustrialização, vida cotidiana, fragmentação, segregação.

\begin{abstract}
By studying the process of deindustrialization and the ongoing restructuring of a fragment of the metropolis of Sao Paulo, the research seeks to understand aspects of reproduction of urbanization at the present time. This fragment, located north of the district of Santo Amaro, is made up from the great decades of industrialization of 1950/60/70, as an industrial area and a place of living of the working class. Industry was the main driver of urbanization of the place, organizing their social life, thus becoming its main reference, producing a fragmented everyday life.

We note, however, that there is a relatively short period of establishment of industry there as early as the late 1980's there is the beginning of the industrial decline in the fragment, a process that is intensified in the 1990s and is accentuated further at the moment. Thus, there is a disintegration of the social life of the fragment due to the removal or closure of industries as bars close, worker housing is vacated and demolished, and many buildings and industrial land remain derelict. At the same time, this area of deindustrialization, for having a privileged position in relation to already established areas as business centers, now include new enterprises related to the "modern" logical of the Southwest business axis,
\end{abstract}

* Mestre e doutorando em Geografia Humana no Departamento de Geografia da Faculdade de Filosofia, Letras e Ciências Humanas da Universidade de São Paulo. Pesquisador do GESP - Grupo de Estudos sobre São Paulo. 
A valorização do espaço de desindustrialização da metrópole:

a produção do espaço como produção da segregação, pp. 105 - 124

106

promoting a radical transformation of spatialities and deepening fragmentation of everyday life as well as socio-spatial segregation.

Key-words: industrialization; urbanization; deindustrialization; everyday life; fragmentation; segregation

\section{Introdução}

A indústria produziu em São Paulo a sua espacialidade e o seu ritmo, induzindo a formação da metrópole. Quando algumas áreas industriais sofrem o processo de saída das indústrias de uma maneira acentuada, podemos vislumbrar elementos da crise social e ambiental que o modo de produção atual produz. Vários fatores corroboram para isso - a reestruturação nas indústrias no sentido de torná-las mais produtivas, o que implica na diminuição de postos de trabalho; o aperfeiçoamento dos meios de comunicação e das vias de transporte que, junto com políticas de industrialização regionais, permitem às empresas custos de produção menores em locais fora da metrópole, separando muitas vezes o local de gestão do local de produção. Em outros casos a indústria entra em crise, deixa de produzir e fecha as portas. Numa metrópole como São Paulo, a reestruturação produtiva e a diminuição do emprego industrial representam um amplo empobrecimento de grande parcela da população, visto que, além da diminuição absoluta no número de empregos, há uma deterioração do trabalho com a perda de garantias e a diminuição de salários. Seja deslocando-se para outro local, seja fechando suas portas, na maioria das vezes ainda permanece o ambiente construído e prováveis resíduos tóxicos que a presença da indústria causou ali. É o que se chama de "passivo industrial", que são as contaminações (de solo, de água) resultantes da atividade industrial e que precisam ser equacionadas para uma possível reutilização do terreno. Outra decorrência que poderíamos apontar como da esfera ambiental é o abandono deste ambiente construído e sua deterioração, que provoca uma deterioração em cadeia de todo o entorno dependente da atividade industrial - bares, restaurantes, casas operárias.

A desindustrialização se configura para nós como um fenômeno identificável na escala local e que, ao mesmo tempo em que é desencadeado por outros processos, produz suas derivações, sendo uma mediação necessária de uma problemática espacial do momento atual. Nas metrópoles a indústria ocupou e ocupa grandes áreas que, em sua maioria, foram incorporadas pela mancha urbana com o crescimento das cidades. No momento em que a indústria diminui a sua produção nestas áreas, desocupa muitos terrenos, revelando a sua localização no contexto da metrópole como fundamental. Estas áreas passam inicialmente por uma inescapável desvalorização, dada a deterioração dos edifícios fabris e do entorno. Podem tornar-se, portanto, áreas 'reserva' para a atuação dos empreendedores imobiliários. Ou seja, podem vir a ser áreas de valorização.

Assim delineia-se a problemática da reestruturação dos espaços industriais que se desindustrializam no interior da metrópole. Chegamos a esta problemática a partir da investigação sobre as implicações sócioespaciais que a desindustrialização está produzindo em uma área em Santo Amaro, zona sul da cidade de São Paulo (mapa 1). Nesta área, situada na várzea do Rio Pinheiros, grandes indústrias vêm se transferindo ou fechando as portas, num processo que produz uma paisagem degradada como a que nos referimos acima. Porém, neste fragmento específico da metrópole, pela sua disponibilidade de espaço e localização, um outro processo correlato se instala: a tendência à sua valorização, com a construção e/ou instalação, nos terrenos industriais, de novos empreendimentos residenciais, comerciais e de serviços. As pessoas que vivem todo esse processo, são mobilizadas a reorganizar e reelaborar os próprios meios de vida, pois são atingidas nos espaços essenciais de sua vida - a sua casa, a rua, o seu trabalho.

A lógica levada a efeito por diferentes grupos econômicos no espaço é a lógica da tecnocracia, gestada na sociedade industrial. A 
A valorização do espaço de desindustrialização da metrópole:

cidade e o espaço da cidade, a partir de determinado momento histórico se tornou o palco privilegiado de ação da tecnocracia capitalista. Se - espaço é dimensão essencial da vida, a reprodução da vida na cidade está subjugada a decisões tecnocráticas que são tomadas nos escritórios das empresas (aqui ou em outros países), nos gabinetes políticos, nas pranchetas dos arquitetos ou nos cálculos dos engenheiros. Primeiro, trata-se da construção de parques industriais na cidade, respeitando as necessidades da produção industrial. Hoje, é da produção do espaço ela mesma que se ocupa a tecnocracia, e, nesse sentido, a localização toma uma importância central. Os esforços, sejam eles estatais ou privados, estão voltados para a valorização do espaço, presumindo-se que esta valorização seja benéfica a todo o conjunto da sociedade. Sob o domínio dessa ideologia, frações da sociedade que vivem o lado negativo da valorização, lutam contra a lógica, explicitando as contradições do urbano. O poder tecnocrático, no entanto, se impõe como a salvaguarda do suposto equilíbrio social e está amparado nas esferas normativas da sociedade, estabelecendo a norma, mesmo se ela provoca a destituição do lugar de moradia de muitos, da rua como possibilidade do encontro, do local de trabalho, do lazer.

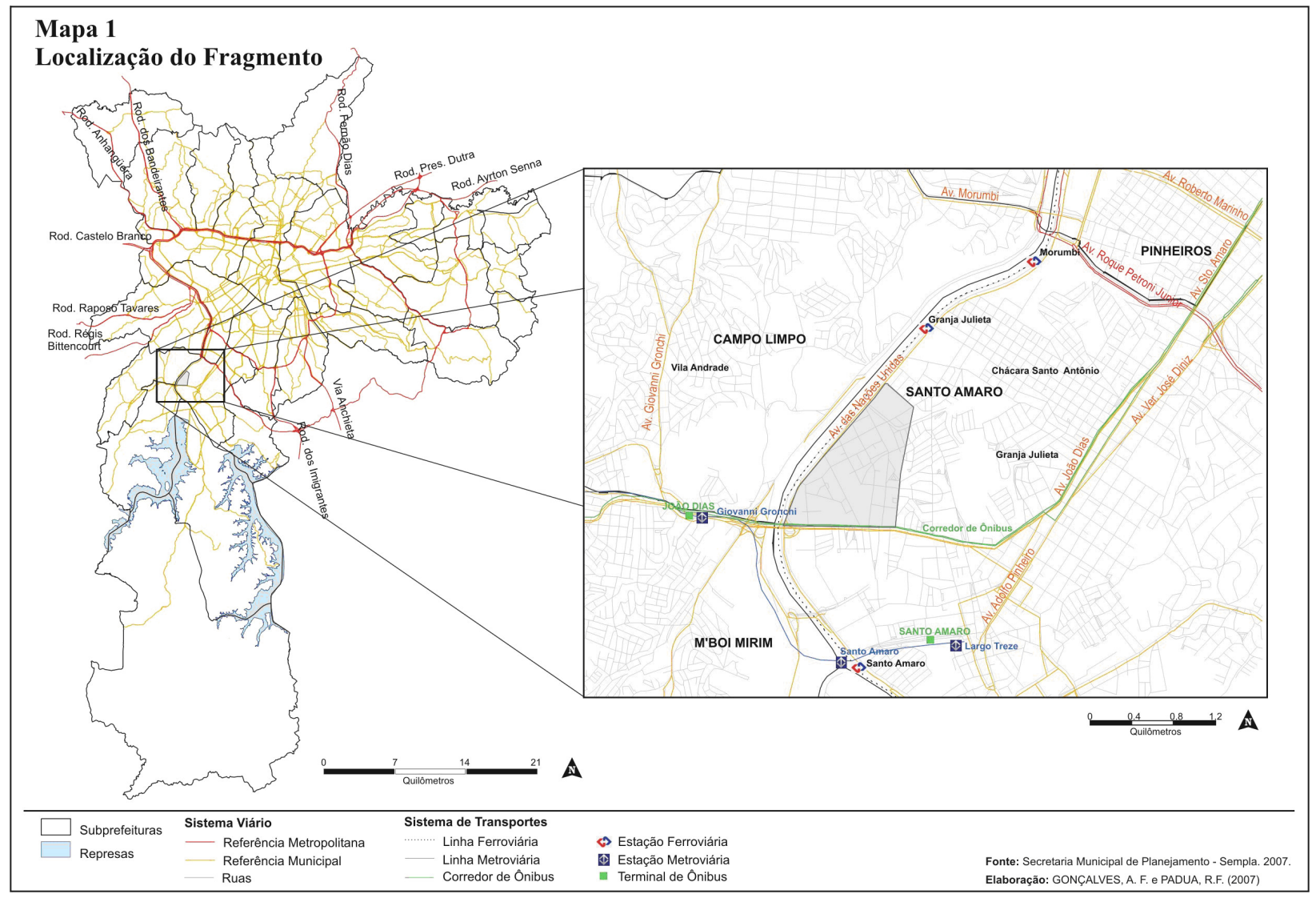

mapa 01 
A lógica industrial esteve assentada na técnica, na transformação contínua dos meios de produção, mas, mais do que isso, na criação de relações sociais de produção que garantissem a sua reprodução. O processo industrial produziu uma práxis, um modo de pensar e de agir e também um espaço específico para sua realização. O novo momento que se vislumbra agora, se mostra como desdobramento da industrialização, que the propiciou as condições de realização. Ao mesmo tempo nega muitas das relações produzidas pela indústria, produzindo novas relações sociais,e, portanto, novas determinações sociais, das quais podemos derivar novas determinações espaciais. O homem, se crinado enquanto homem, produz 0 seu espaço, produzindo espacialidades que são expressões reais das determinações sociais que vêm da história. Assim, a espacialidade produzida pode ser considerada como uma esfera da práxis, que é determinada historicamente. A indústria, a instauração do cotidiano, a constituição e crescimento do mundo da mercadoria, instituindo o próprio espaço como mercadoria, são elementos determinantes da vida social.

Quando refletimos sobre a urbanização que ocorreu em São Paulo a partir da década de 1950, nos deparamos com uma grande massa de trabalhadores migrantes que iam fazer parte da grande classe operária da cidade. A metrópole impõe seu ritmo à vida das pessoas, as conforma no tempo acelerado do mundo do trabalho fabril, dos deslocamentos diários, do esforço pela reprodução da família, das possibilidades esmagadas de lazer. O mundo da fábrica, o mundo da vida familiar, o mundo da rua e o mundo do lazer, se realizam como espaços-tempos que aparentemente se autonomizam, mas que formam a unidade da vida cotidiana na metrópole. A metrópole incorpora as pessoas moldando-as em uma prática sócioespacial fragmentada, produzida pelas necessidades da reprodução econômica. Quando o setor industrial entra em crise, diminui as possibilidades de trabalho para a grande classe operária, deteriorando ainda mais a vida na cidade. As espacialidades que vão se produzindo na metrópole manifestam as transformações no conjunto da classe operária e as suas novas possibilidades de reprodução na metrópole, assim como mostram também que a ação da lógica abstrata da reprodução do capital produz novas contradições que se revelam como contradições do espaço.

A fábrica fordista, que concentrava uma grande quantidade de trabalhadores em suas plantas, apesar de representar o catalisador da dominação da vida, fragmentando-a, era, contraditoriamente um lugar de sociabilidade, onde os trabalhadores, a despeito de todo o peso da supervisão, criavam formas de reflexão da própria prática: nos momentos de descanso, na saída e entrada do trabalho, nas conversas cotidianas entre colegas, nos bares e restaurantes das esquinas. Com a reestruturação produtiva que gradativa ou rapidamente toma as plantas industriais, quebram-se ainda mais esses laços criados pela atividade industrial. A vida fragmentada se torna ainda mais empobrecida, porque mais instável, mais distante dos laços de sociabilidade criados com o tempo.

\section{A desindustrialização na passagem da primazia do capital industrial para a primazia do capital financeiro}

Partimos da constatação de que a metrópole de São Paulo vive, acompanhando o movimento geral da economia capitalista, um momento de passagem da primazia do capital industrial para a primazia do capital financeiro ${ }^{2}$, fato que é mais evidente na produção de novas centralidades no seu tecido urbano, destacando aqui o eixo de valorização do vetor sudoeste (mapa 2). A produção do espaço se apresenta, cada vez mais, como mediação fundamental para a valorização de capitais da esfera financeira. Neste processo, se delineia uma problemática importante, que é aquela dos espaços onde a indústria se concentrou e que agora perdem, ao menos relativamente, o seu papel industrial. A reestruturação dos espaços industriais se realiza de duas formas distintas. Em muitos desses locais outras atividades como universidades, empresas de transporte, igrejas, passam a ocupar o espaço da indústria, aproveitando os edifícios industriais para as novas instalações ${ }^{3}$. Em outros locais, o 
A valorização do espaço de desindustrialização da metrópole:

que se apresenta é uma reestruturação mais profunda em direção à inserção desses espaços aos circuitos modernos da economia, o que leva não só a uma transformação física dos edifícios, mas a uma valorização do espaço. Nesse segundo caso, a localização dos terrenos é fundamental.

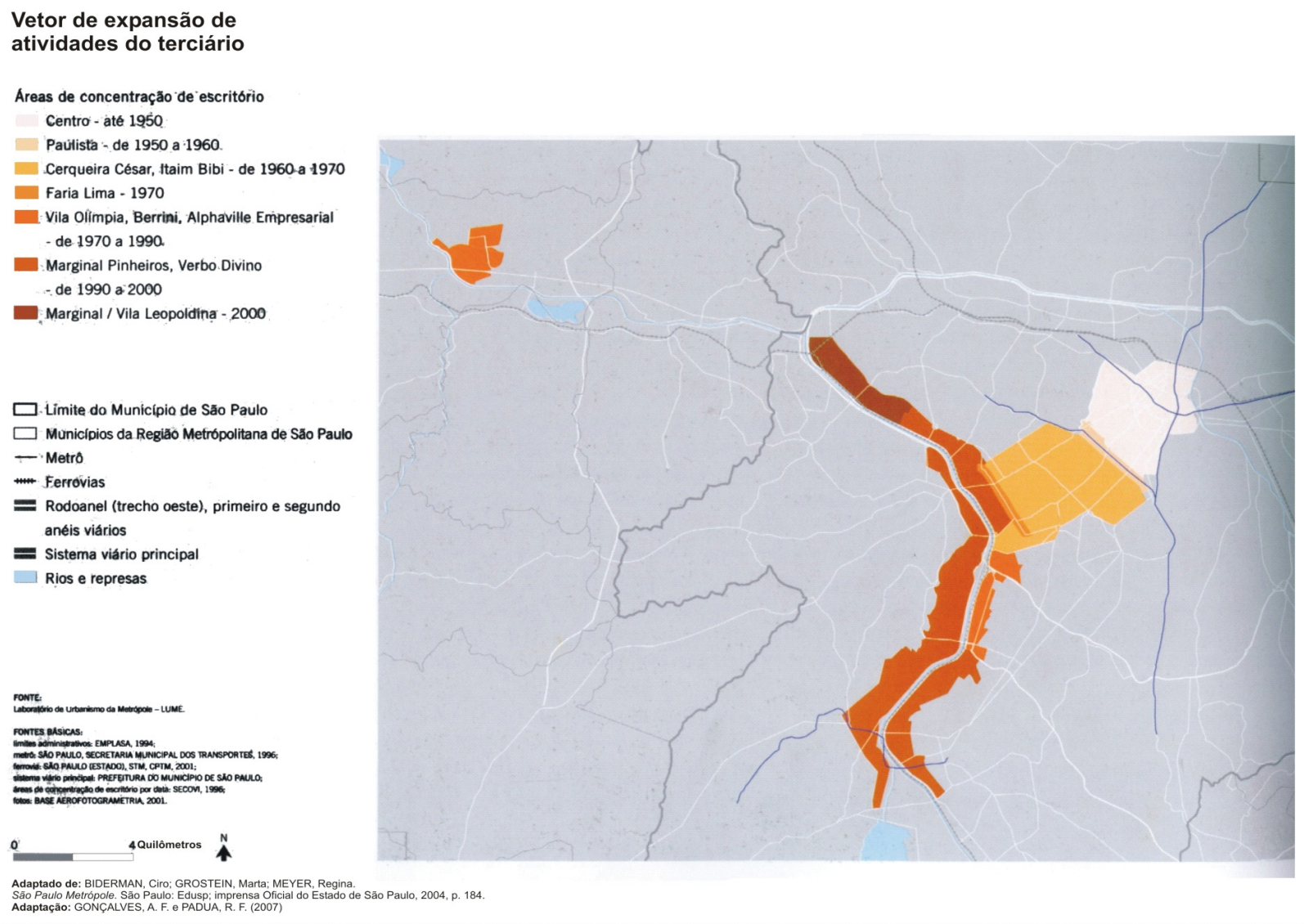

mapa 02

É certo, por outro lado, que a indústria capitaneou por muito tempo as diretrizes da produção da cidade e foi o principal motor da grande acumulação de inúmeros elementos que configuraram São Paulo como uma metrópole. Trata-se de um processo de transformação contínuo que, ao mesmo tempo em que impõe mudanças e rupturas em relação ao que havia anteriormente, evidencia persistências na paisagem e nas práticas sócioespaciais da metrópole. Este movimento de transformação não significa o desaparecimento da indústria em São
Paulo, mas a sua reprodução num momento em que a hegemonia nas diretrizes dos mecanismos da acumulação ampliada passa , cada vez mais, a se localizar no âmbito do financeiro.

É preciso deixar claro que em São Paulo não há um processo generalizado de desindustrialização, visto que a atividade industrial ainda tem um peso significativo no conjunto de suas atividades econômicas. Evidentemente, há um processo de 
desconcentração industrial, ao mesmo tempo em que há uma centralização da gestão das empresas em São Paulo ${ }^{4}$. Observa-se que, muitas vezes, a planta industrial se desloca para outra região, mas a gestão da empresa permanece em São Paulo, que passa a concentrar as condições propícias para as atividades de gestão, que demandam serviços de toda ordem ${ }^{5}$. O conceito de desindustrialização está ligado, nesta perspectiva, a determinadas áreas no interior da metrópole onde a indústria era a atividade predominante e perde terreno para outras atividades econômicas ou deixa de existir.

O fragmento que estamos estudando na pesquisa localiza-se ao norte do distrito de Santo Amaro, na região sudoeste de São Paulo e se desindustrializa com uma certa velocidade a partir do início da década de 1990. É uma área onde originalmente se instalaram grandes indústrias intercaladas por conjuntos de pequenas casas operárias. A localização desta área a integra, tendencialmente, como a ponta sul do eixo de valorização do vetor sudoeste. Alguns elementos corroboram para esta hipótese: a grande oferta de terrenos (industriais) com uma localização privilegiada no contexto metropolitano; a recente instalação de grandes e requintadas casas de eventos e shows que aproveitam, em parte, antigos edifícios industriais; lançamentos de novos "produtos" imobiliários residenciais voltados para a classe média alta; instalação de concessionárias de automóveis em edifícios industriais. Estes novos elementos que passam a compor a paisagem e as relações que eles passam a produzir no fragmento, nos levam a pensar este momento como intermediário entre um local voltado para a produção industrial e um local tomado pelas estratégias de valorização capitaneadas pelos agentes do capital financeiro, articulados aos investidores imobiliários e empresários da construção civil.

\section{A integração dos espaços de desindustrialização aos circuitos dinâmicos da economia}

A própria paisagem da metrópole indica desigualdades sócioespaciais que podem apontar, para a análise, os processos mais gerais que regem a sociedade. No espaço da Região Metropolitana de São Paulo como um todo, várias áreas de concentração industrial se desindustrializam Estas áreas, constituídas em diferentes momentos da história da industrialização da Região Metropolitana, tomam, hoje, diferentes sentidos na reprodução da metrópole (mapa 3). A reestruturação destes espaços industriais no sentido da instalação de outras atividades econômicas diferentes da industrial se realiza de acordo com o papel de cada área no contexto da metrópole hoje. As áreas onde se verifica a desindustrialização, ao mesmo tempo em que passam por uma desvalorização e até mesmo por uma deterioração física dos edifícios industriais, se tornam áreas de disponibilidades de terrenos passíveis de valorização por parte do mercado imobiliário. Desse modo, de acordo com a localização e acesso da área, tornam-se a sua nova inserção nesse novo momento da economia paulistana, ou não dar-se -á, permanecendo, neste caso, como um espaço reserva para possíveis investimentos futuros.

Para os investidores imobiliários e os empresários da construção civil (cada vez mais articulados ao mercado financeiro), impõe-se a integração contínua de novos espaços nos processos econômicos mais dinâmicos da metrópole, para a reprodução de seus capitais. Com essa finalidade, produzem muitas estratégias, inclusive se utilizando de prerrogativas favoráveis que Ihes concede o Estado, procurando conceber um crescimento econômico cada vez mais expansivo e que favoreceria, segundo este discurso oficial, à sociedade como um todo. Neste discurso dos agentes econômicos acima elencados, assim como no discurso dos representantes do Estado, as transformações por que passam algumas áreas de desindustrialização são processos "naturais" de reconfiguração de atividades econômicas da cidade, passando da atividade fabril, composta por um grande número de trabalhadores de linha de montagem, para atividades ligadas aos serviços, que seriam exercidas por trabalhadores com maior qualificação e com maior poder aquisitivo. Outro elemento deste momento são os novos empreendimentos residenciais voltados 
A valorização do espaço de desindustrialização da metrópole:

a produção do espaço como produção da segregação, pp. $105-124$

para a classe média alta nestas áreas antes predominantemente industriais, que, para este discurso tecnocrático, também representam um avanço econômico para estas áreas. Para nós, num primeiro momento, a instalação destes novos equipamentos urbanos onde somente havia indústrias, pequenas casas, bares populares e terrenos vazios produz uma paisagem com extremas desigualdades sócioespaciais, evidenciando novas tendências na produção do espaço da metrópole.

O discurso do econômico articulado ao político emplaca a tese da mudança de "vocação" da área no sentido do desenvolvimento ${ }^{6}$ de São Paulo como uma cidade de negócios e de serviços modernos. É um discurso divulgado em diversos meios, elegendo áreas passíveis de maior valorização, que pretende criar tendências de valorização ou consolidá-las, constituindo novas fronteiras para os setores articulados da incorporação imobiliária, construção civil, mercado financeiro.

Na metrópole de São Paulo, o eixo mais expressivo de valorização é aquele na direção sudoeste. A consolidação desse eixo indica a tendência de sua extensão, englobando espaços mais adiante. A área em processo de desindustrialização do norte do distrito de Santo Amaro se apresenta, para os agentes da valorização, como um amplo espaço para suas estratégias, mesmo contando, entre os grandes galpões industriais, com conjuntos de pequenas casas operárias.

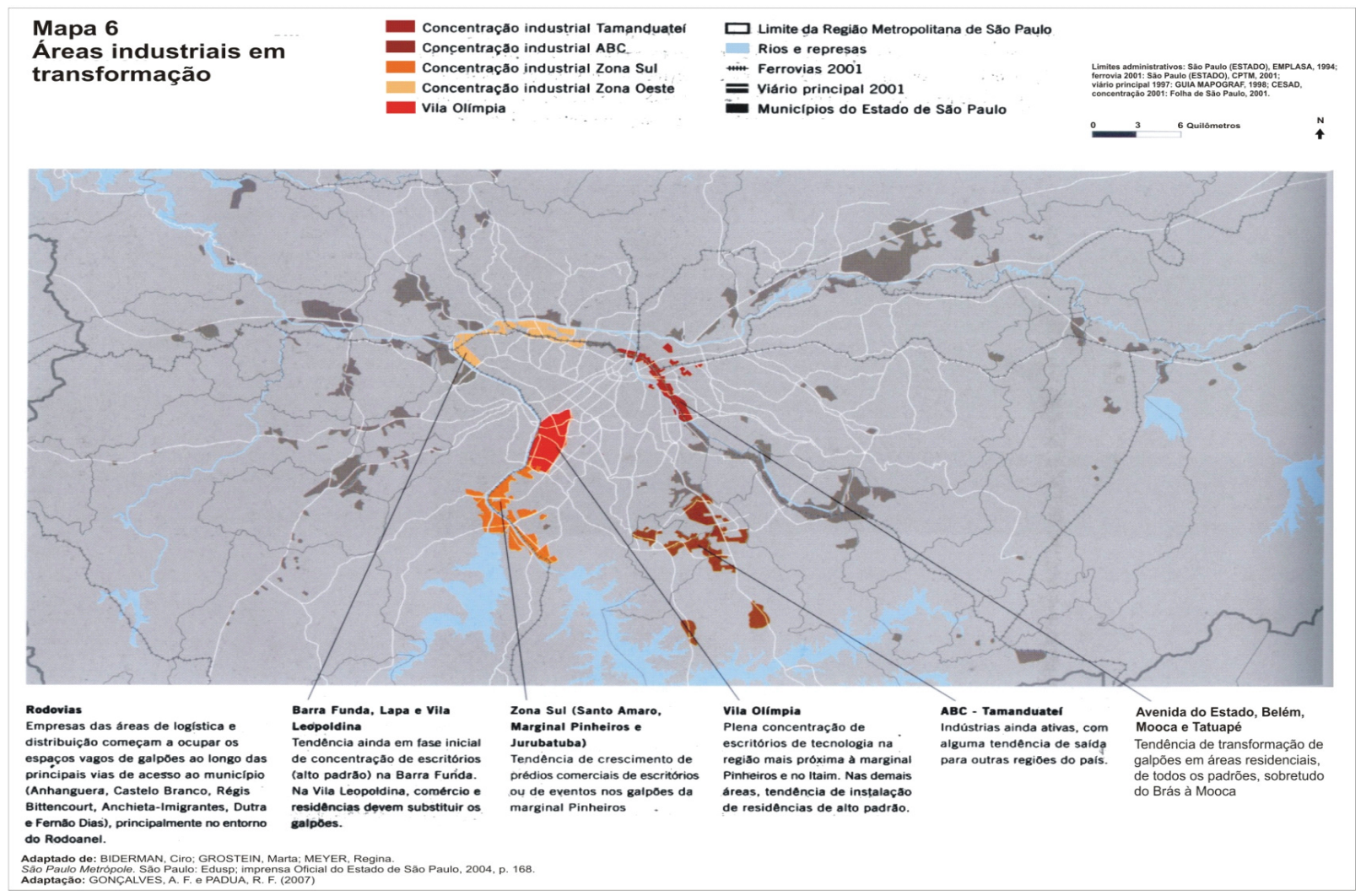

mapa 03 


\section{Algumas hipóteses}

No momento atual, identificamos uma transformação na dinâmica econômica, na qual a produção industrial perde importância e aumenta o peso das atividades terciárias. Articulado a este processo, verificamos no momento atual o avanço das atividades de serviços e condomínios residenciais sobre espaços de desindustrialização na direção sudoeste. Isto substancia a hipótese de que há um aprofundamento da fragmentação da vida com a transformação dos espaços industriais neste momento da urbanização.

O processo de instalação de novos equipamentos urbanos, sejam eles para moradia das classes de alto poder aquisitivo, sejam as atividades de serviços, não incorporam o outro do processo, que são as pessoas que ali moram há décadas. Conforma-se, cada vez mais, um processo segregador. Mesmo que a mobilização dos moradores daquele lugar não seja absoluta, é um processo de destituição dos espaços habituais de sociabilidade (a rua, a calçada, a vila de moradores). Este processo se apresenta também como uma destituição de relações, pois separa entre si os moradores que permanecem, ao mesmo tempo em que separa aqueles que ali trabalhavam e perdem o emprego, ou aqueles que lá moravam e vão para outros lugares. O sentido da permanência das pessoas, sejam elas moradoras, sejam elas trabalhadores naquele local, está cada vez mais incerta.

Mesmo num espaço já constituído pela fragmentação imposta pelo ritmo da indústria, ali se constituíram, contraditoriamente, laços fortes de sociabilidade. É um lugar de referência para muitas famílias que ali se estabeleceram, geralmente vindas de lugares distantes do país, movidas pela industrialização galopante de São Paulo. Para a criação da identidade, a permanência no lugar de referência da vida, é fundamental. As relações de proximidade, de vizinhança, ou com colegas de fábrica, ficam incertas, ou desaparecem, ou permanecem sob novas condições de existência. Assim, há um empobrecimento da vida, quando processos segregadores avançam e se impõem no fragmento.

\section{Os novos empreendimentos de shows e eventos}

São Paulo se revela no contexto brasileiro, como a metrópole que liga a economia nacional com a economia mundial, acompanhando as transformações econômicas mundiais e se transformando com elas. Por diversos meios divulga-se o crescimento do setor de serviços, e a constituição de eixos de prosperidade em contradição com a crise da indústria e do emprego industrial.

São Paulo deixa para trás cada vez mais o seu perfil de centro eminentemente industrial para se tornar uma capital voltada para a prestação de serviços de todo tipo. Não é à toa que, entre os maiores empregadores na região, apenas dois a Volkswagen, com 18000 funcionários, e a Mercedes-Benz, com 10200 - pertencem ao ramo industrial. Todos os outros estão ligados a atividades como comércio, finanças, alimentação, hotelaria, comunicações, limpeza e segurança?

O eixo sudoeste é o foco principal desta nova fase da metrópole, representando o lugar da espacialização da "positividade" da globalização, com a configuração de uma metrópole onde o "ambiente" para os negócios, para a economia moderna, está potencializado. "Aqui se reúnem todos os fatores de competitividade indispensáveis para as empresas que utilizam a tecnologia de modo intenso: engenheiros, administradores e técnicos especializados, assim como as redes articuladas de clientes e fornecedores" 18 . Este, com certeza, é um aspecto que se impõe em São Paulo, descrevendo uma dinâmica que a metrópole passa a concentrar em relação ao Brasil. No entanto, é necessário examinar criticamente esta "positividade" da "cidade dos negócios" para o conjunto da sociedade e para o conjunto da cidade. Verificamos hoje que o capital se concentra crescentemente e, mesmo espacialmente, cria as suas áreas propícias de atuação. É assim que entendemos o crescimento, em direção ao sudoeste da cidade, do setor de gestão, de comando empresarial, do setor comercial e de 
A valorização do espaço de desindustrialização da metrópole:

a produção do espaço como produção da segregação, pp. $105-124$

serviços. Nesta área de expansão, produz-se uma paisagem e novas relações que representam o moderno na metrópole. Novos espaços se tornam necessários para propiciar maior agilidade às trocas necessárias à realização dos negócios. O crescimento do turismo de negócios em São Paulo indica a confirmação desta tendência.

Nove em cada dez feiras ou convenções que ocorrem no país têm lugar em São Paulo. Isso significa, no ano passado [1999], 4,2 milhões de visitantes. O negócio dos eventos vem crescendo a taxas de $5 \%$ a $7 \%$ ao ano, e só não avança mais depressa pela falta de áreas capazes de abrigar as grandes feiras internacionais ${ }^{9}$.

O setor de eventos alça-se como um dos mais representativos deste novo momento, surgindo como uma das "vanguardas" das novas atividades de serviços da metrópole. Novos equipamentos culturais, grandes casas de shows, entretenimento e eventos avançam na direção sudoeste: Teatro Alfa, Credicard Hall, Tom Brasil, Villa Noah, entre outros. As novas relações, baseadas em uma prática voltada aos negócios, ficam evidentes quanto se trata dos eventos. Os eventos se tornam uma nova frente de negócios nesta parcela da cidade que se pretende mundial.

Pessoas reunidas. Emoção. Valores estéticos. Sabores inesquecíveis. Parcerias seladas. Abraços fraternos. Negócios fechados. Organizar eventos é viabilizar sonhos. Prever o imprevisível. Concretizar idéias. Nada pode dar errado. O que parece tão simples requer prática, agilidade e profissionalismo. O Tom Brasil já divertiu, emocionou, serviu e encantou mais de 500.000 pessoas em quase 4.000 eventos. Desde um simples coffebreak até congressos e convenções, nós nos ocupamos de todas as etapas para que você tenha tranquilidade e segurança ${ }^{10}$.

Os eventos são um novo produto que promove outros produtos. As empresas promotoras de eventos, se tornam, elas mesmas, uma marca. Produzem eventos de todo tipo, desde casamentos e festas de aniversários, até convenções de grandes empresas, com shows e festas de grande porte. Duas destas grandes casas de eventos nos interessam mais, pela localização na Várzea de Baixo: o Tom Brasil e o Villa Noah Embratel. A presença de terrenos e edifícios industriais de grande porte disponíveis para novos usos nesta área é fundamental para a instalação desses novos equipamentos. Esse movimento de transformação dos usos do lugar se assemelha, embora com algumas características diferentes, ao que ocorreu na Vila Olímpia na década passada:
Casas noturnas, bares e danceterias surgiram em locais antes ocupados por fábricas de médio porte. Grandes áreas viraram estacionamentos para atender à grande demanda. Campo de futebol virou condomínio com torres, abrigando mais de 1000 pessoas $^{11}$.

Indústrias que ocupavam grandes áreas deixaram de existir para se tornarem "as megas casas de shows e eventos", como o Tom Brasil e a Via Funchal, isto em 1998 e hoje em dia já estão também sendo ameaçadas por mega empreendimentos e principalmente pela falta de estacionamento que está se tornando raro na Vila Olímpia $^{12}$.

Na Vila Olímpia, onde a transformação do uso do solo foi avassaladora, podemos verificar os momentos dessa transformação. Grandes casas de shows e eventos - Tom Brasil e Via Funchal se instalaram ali num primeiro momento de constituição das novas atividades comerciais e de serviços, permanecendo, no caso do Tom Brasil, um curto período neste lugar. A concentração de 
edifícios de escritórios, assim como de novos condomínios residenciais na Vila Olímpia, que contribuiram para a valorização dos terrenos da área, passam a dificultar a realização destas atividades aí, pois elas necessitam de amplos espaços tanto para a realização dos eventos e shows como para os estacionamentos. Assim podemos concluir que o uso dos galpões e terrenos para essas atividades de entretenimento, eventos e shows, pode significar um momento inicial da valorização de um fragmento da metrópole, que tendencialmente pode se tornar uma nova centralidade de atividades do terciário moderno. A casa de shows e eventos Tom Brasil, que inicialmente se instalou na Vila Olímpia (inaugurada em 1998), em 2003 inaugura as sua novas instalações, o Tom Brasil Nações Unidas. A casa da Vila Olímpia é desativada pouco tempo depois. Hoje, no espaço onde ela se situava, ergue-se um grande edifício de escritórios. A nova casa do Tom Brasil na Várzea de Baixo representou o primeiro sinal de mudança efetiva de transformação dessa área. Já se verificava o processo de saída das indústrias, assim também como outras atividades terciárias de grande porte já estavam instaladas ali, como concessionária de carros, mas o significado e o novo movimento que a casa de shows produz, a tornam uma nova referência na área, como era anteriormente, por exemplo, a Bosch.

No que se refere à realização de espetáculos, o Tom Brasil se coloca ao lado do Credicard Hall, como uma das grandes casas de shows de São Paulo, concentrando atrações de todos os gêneros musicais, nacionais e internacionais. Ao mesmo tempo, é também uma grande casa de eventos, com uma estrutura nesse sentido. Dispõe de três ambientes diferentes $\left(2400 \mathrm{~m}^{2}, 450 \mathrm{~m}^{2}\right.$ e $300 \mathrm{~m}^{2}$, respectivamente) para a realização de coquetéis, jantares, convenções em formato de auditório e eventos com shows, que contam com refinados equipamentos de som e multimídia, e possibilitam a realização de eventos que podem reunir de 160 pessoas (evento com show no menor espaço disponível), até 4500 pessoas (evento com show no maior espaço disponível) ${ }^{13}$. Além dessa estrutura interna, há também a disponibilidade de estacionamentos em grandes terrenos das redondezas transformados para esse fim, que servem também a outras casas de eventos.

O outro empreendimento voltado para a realização de eventos que se sobressai no fragmento é o Villa Noah Embratel, inaugurado em 2005 em galpões onde antes funcionava uma tecelagem. Diferentemente do Tom Brasil, cujas atividades abrangem eventos e shows, o Villa Noah é especializado na realização de eventos. Possui uma ampla infraestrutura, constituída por "3 salões de 300 a $750 m^{2}$; duas salas de apoio de $32 m^{2}$ e $49 m^{2} ; 2$ foyers de $106 m^{2}$ e $260 m^{2} ; 1$ terraço de $250 \mathrm{~m}^{2}$; 1 sala vip/camarim de $20,30 \mathrm{~m}^{2} ; 1$ business center de 12,70m²; 3 chapelarias/secretarias; 2 entradas sociais independentes; 4 conjuntos de toaletes; espaço gatronômico $1500 m^{2}$, com capacidade para até 1600 pessoas"14, contando ainda com um estacionamento para 600 carros. Os seus ambientes são equipados com um grande aparato técnico, que compreende "gerador de emergência; internet rápida (wireless); telefonia digital; acústica adequada para diversos tipos de eventos; instalações flexíveis; controle independente de iluminação e ar condicionado; cozinha projetada para atender 6 mil refeições/dia"15. Esta estrutura, instalada em um antigo edifício industrial, evidencia a radical transformação do uso, mesmo que se mantenha o aspecto original do edifício. Todo este espaço e o aparato técnico nele instalado permitem a realização de vários eventos simultaneamente, evidenciando, juntamente com a presença do Tom Brasil ${ }^{16}$ e outras casas de eventos médias e pequenas e outras atividades comerciais, a tendência para a constituição ali de uma nova centralidade de atividades terciárias em São Paulo.

\section{Os novos empreendimentos residenciais}

No movimento de transformação do espaço de desindustrialização objeto deste estudo, verificamos também o avanço de novos e grandes empreendimentos residenciais, que são lançados em amplos terrenos antes ocupados por indústrias ou sem uso específico (terrenos estes que 
A valorização do espaço de desindustrialização da metrópole:

a produção do espaço como produção da segregação, pp. $105-124$

permaneceram um tempo como objeto de especulação).

Os empreendimentos são de grandes construtoras de São Paulo, como Tecnisa, Even, Klabin/Segal, articuladas a incorporadores, como Quality e a imobiliárias como I-Price e Lopes. Este espaço vai sendo incorporado estrategicamente por grandes empresas, que se aproveitam da grande disponibilidade de terrenos para a construção de seus "novos produtos imobiliários"17

$\mathrm{Na}$ fala dos corretores ${ }^{18}$, esta área passa a ser interessante para este tipo de empreendimento porque tem uma localização privilegiada, possibilitando um fácil acesso a vários lugares da cidade que hoje se configuram como novas centralidades (região sudoeste), onde passa a se localizar uma grande quantidade de empresas, que por sua vez atrairiam novos moradores para a região. Ao lado deste fator localização/acesso, está o preço do metro quadrado, que aí é muito inferior às regiões mais densificadas do eixo de valorização sudoeste. Outro fator importante é aquele da maior facilidade de negociação para as construtoras quando se trata da compra de um terreno industrial, que geralmente tem um único dono e o custo de demolição é menor do que em um terreno residencial, onde a negociação seria com vários donos diferentes. Neste sentido, duas áreas de desindustrialização se apresentam como lugares de avanço dos novos empreendimentos residenciais: Vila Leopoldina (a que tem, segundo os corretores, maior potencial de construção de "residenciais") e a região de Santo Amaro. Nestas duas áreas, as construtoras encontram uma maior disponibilidade de terrenos com o custo do metro quadrado menor e com uma metragem condizente com a construção de grandes condomínios residenciais de alto padrão (novos produtos imobiliários), com grandes áreas de lazer. Se a área disponível se situa em um espaço até recentemente dominado por grandes galpões industriais e que ainda guarda o aspecto da indústria, mas hoje com uma certa deterioração, em um lugar que não tem ainda o uso residencial predominante, isso importa pouco para os empreendedores, que produzem condomínios fechados que nada tem a ver com o entorno, "novos produtos imobiliários" que negam o entorno, ou o utilizam naquilo que promova o empreendimento, como a localização e/ou acessibilidade a áreas privilegiadas da metrópole. O fato dessas duas principais áreas estarem localizadas próximas à Marginal do Rio Pinheiros é muito bem explorado pelos empreendedores.

O marketing é um elemento importante a ser ressaltado, pois é preciso atrair possíveis consumidores para o produto imobiliário em uma área que não é consolidadamente residencial. Assim, usa-se de diversos meios para tornar o empreendimento conhecido: programas de publicidade televisiva; anúncio em jornal; bandeiras; distribuição de folhetos no trânsito e em hipermercados da região; faixas. Ou seja, uma publicidade ostensiva, voltada para a realização dos "novos produtos imobiliários".

Considerando o conjunto dos novos empreendimentos residenciais dessa área específica, a concorrência entre eles não é um fator que atrapalha uns aos outros, pelo contrário, a propaganda realizada por um pode ajudar o outro, já que pessoas que foram atraídas por determinado empreendimento residencial, podem acabar se interessando e comprando o apartamento de um outro que está próximo. Contribui para isso o fato de que são "produtos imobiliários" voltados para um mesmo perfil de consumidor, de classe média-alta. Dessa forma, a propaganda realizada por cada empreendimento acaba, no conjunto, contribuindo para a divulgação de todos os empreendimentos que se localizam próximos. No caso específico deste espaço de desindustrialização, o lançamento e construção de vários condomínios residenciais ao mesmo tempo ajuda a configurar uma área de expansão para este tipo de empreendimento. Mesmo que os corretores ressaltem não se tratar de uma estratégia conjunta das construtoras, admitem que isso acaba aquecendo o mercado.

Como o apartamento é um produto especial, pois se trata de um uso para moradia, os empreendimentos têm que ter elementos que seduzam possíveis compradores, se utilizando para isso de inúmeros discursos que envolvem o 
conforto, o lazer, a segurança, além da acessibilidade e da localização.

A estrutura desses "novos produtos imobiliários" consiste na otimização do aproveitamento do terreno, procurando oferecer um refinamento nas possibilidades de lazer, tanto nas áreas comuns quanto na área privativa de cada apartamento. O desenho dos projetos busca seguir linhas clássicas de fachada e uma estética nova nos espaços interiores do empreendimento. O aprimoramento dos espaços de lazer é com certeza o principal elemento que procura diferenciar os novos empreendimentos, difundindo o que os seus catálogos de propaganda chamam de "um novo estilo de viver", se autopromovendo como um oásis de tranquilidade dentro da cidade problemática, violenta, estressante e caótica. Além dos tradicionais playground para as crianças, piscina, e salão de festas, os novos empreendimentos se equipam com outros espaços que procuram sanar o estresse produzido pela correria do dia-a-dia da metrópole. Assim, são oferecidos, nesse propósito, atelier de pintura; spa; redário; tenda de massagem; ofurô; espaço zen; ambiente dedicado à estética. Apresentando essas novas opções de lazer, um catálogo de um dos empreendimentos afirma o seguinte:

Deite-se numa cama sob pergolado. Relaxe na tenda de massagem ao ar livre. Renove-se no spa com sauna. Passe duas horas no beauty care. Banhe-se no ofurô e medite no espaço zen. Ou simplesmente fique de papo pro ar no redário. As modalidades focadas no bem-estar mental são tantas que você pode fazer uma a cada dia da semana. Todos esses ambientes estão concentrados num mesmo setor do terreno, integrando melhor as atividades e proporcionando maior privacidade aos moradores.

Dentro deste espectro de lazeres disponíveis ressalta-se também os espaços dedicados aos esportes e cuidados com o corpo: sala de fitness, quadra poliesportiva, piscina coberta e piscina descoberta, quadras de tênis, quadra de squash, salão de jogos.

O cuidado com o corpo é um hábito saudável e essencial que o homem moderno já incorporou ao seu dia-a-dia. Numa cidade movimentada como São Paulo, onde quase tudo é trabalho, estudo e corre-corre, os momentos de lazer, ginástica e contato com a natureza assumem uma importância ainda maior. Ainda bem que existe uma proposta de vida como o $\mathrm{XXX}^{19}$.

Novos espaços dedicados à gastronomia: espaço gourmet, com churrasqueira ao lado, forno de pizza, hamburgueria; as varandas dos apartamentos, agora mais espaçosas, são equipadas com churrasqueiras. Locais diferenciados para as festas: salão de festas adulto e salão de festas infantil. Novos espaços: Ian house, sala de cinema, child care.

Quando compra o apartamento, o morador está comprando todo um pacote que promete um certo "estilo de vida" moderno, "ligth" e em harmonia com a natureza. É a produção de uma vida cada vez mais privatizada, vivida em espaços fechados, que nega a cidade, e baseada em pressupostos ideológicos, abstrações que se concretizam ainda mais na vida dos habitantes da metrópole. Produz-se tudo isso como se fosse um "estilo de vida", o que não passa de um estetismo, produzido por relações ainda mais mediatizadas pelo mundo da mercadoria, que afirma e desevolve estas relações. O condomínio oferece uma gama enorme de opções de atividades para que o morador tenha que sair o menos possível. O contato com a natureza é também fortemente enfatizado, a ponto de induzir a idéia de que, avistar o Parque Burle Marx do outro lado da Marginal do Rio Pinheiros, ou cruzar com vasos de plantas e pequenas árvores espalhados pelo condomínio representam este almejado contato com a natureza. São empreendimentos produzidos, como dissemos 
A valorização do espaço de desindustrialização da metrópole:

a produção do espaço como produção da segregação, pp. $105-124$

acima, visando novas necessidades sociais. A cidade aparece como algo perigoso aos seus habitantes, com a violência, com o estresse produzido pela vida urbana, o que faz com que as pessoas (das classes média-alta e alta) passem a ter necessidade de se encastelar cada vez mais, se autosegregando do contexto urbano em que estão inseridos. Ao mesmo tempo, a produção desses novos espaços contribui para a afirmação desta "nova necessidade", produzindo um estetismo do morar, um "morar com uma nova qualidade de vida", morar num espaço que confere um "status" a quem nele mora. Um "novo estilo de vida", um novo "status", é o que também representa para o morador a compra do imóvel, segundo os catálogos promocionais desses empreendimentos.

O principal público para os maiores apartamentos disponíveis (135 $\mathrm{m}^{2}$ a $207 \mathrm{~m}^{2}$ ), segundo os mesmos corretores entrevistados, geralmente é formado por famílias da própria região sul-sudoeste de São Paulo (expandida), de bairros onde o metro quadrado é mais valorizado, como Moema, Campo Belo, Brooklin. É um público que já tem o seu conjunto de atividades cotidianas (trabalho, escola, lazer, etc.) estabelecidas na região e muitas vezes quer um apartamento maior, mas não tem condições de comprar nessas áreas mais valorizadas. Outro perfil de comprador para esses empreendimentos, interessado nos menores apartamentos $\left(103 \mathrm{~m}^{2}\right)$, é formado por jovens casais que trabalham em empresas da região.

\section{O avanço dos novos empreendimentos como avanço da fronteira econômica sobre o fragmento e aprofundamento da fragmentação}

O sentido do termo centralidade, na tendência que estamos examinando, do avanço de novas centralidades na direção sudoeste da metrópole de São Paulo corresponde, na verdade, a um empobrecimento da noção de centralidade. Com a expansão da mercadoria sobre o espaço urbano, o centro histórico se esvazia de seu sentido simbólico, é implodido. Constituem-se, no tecido urbano, outras centralidades produzidas de acordo com a lógica e a linguagem da mercadoria, como produto ${ }^{20}$. O sentido econômico dessas novas centralidades se utiliza dos atributos de centralidade urbanos mas os subverte através da funcionalização dos espaços, produzindo espaços privatizados e especializados, com finalidades econômicas específicas e para públicos específicos. Tanto os espaços para as atividades comerciais e de serviços (principalmente as casas de eventos e de shows), como os novos espaços residenciais, são produzidos como espaços de consumo consumo de eventos de negócios, de eventos "culturais", de entretenimento, de música, de serviços gerais, e o consumo de um "novo estilo de vida" nos novos condomínios residenciais. Este sentido da centralidade impõe uma nova lógica ao lugar onde está se inserindo (a lógica de um lugar de consumo, com seu movimento característico), destituindo por outro lado, funções centrais, como a moradia de muitas pessoas que ali estão há algumas décadas. A centralidade industrial, ela também problemática do ponto de vista do sentido concreto de centralidade, dá lugar, no fragmento, a uma centralidade ainda mais contraditória, porque mais segregadora, que é aquela das atividades terciárias.

Por outro lado, com a crescente fragmentação da vida cotidiana na metrópole há uma demanda, cada vez mais reprimida, do verdadeiro sentido de centralidade. Esta demanda pode ser identificada nos irredutíveis presentes nos espaços/momentos da vida cotidiana e que negam, episodicamente, a fragmentação. Essa demanda de centralidade concreta, manifesta a contradição presente na vida urbana entre a necessidade de centro e a negação da centralidade. As novas centralidades abstratas voltadas para as atividades terciárias modernas impõem outras necessidades - afirmação da lógica da cidade do carro, espaços onde o funcionamento é totalmente previsível, totalmente fechados ao entorno, enfim, espaços estritamente produzidos para determinadas finalidades, cujo uso pressupõe a mediação de uma quantia de dinheiro.

Consideramos que os novos espaços que vão sendo configurados por esta produção econômica do espaço, que constitui novas centralidades voltadas para o consumo e a moradia de uma classe de alto poder aquisitivo, evidencia 
o aprofundamento de um modo de vida baseado em uma extrema organização dos espaços/tempos da vida cotidiana, em que todos os deslocamentos são feitos de carro, as atividades diárias se fazem em locais específicos. Esquematizando, seria a organização da vida dividida entre a moradia, o trabalho ou estudo, o lazer, os tempos obrigatórios e entre estes momentos os deslocamentos dentro do carro. A rua, esvaziada se torna estrito lugar de passagem, destroem-se as relações de vizinhança, os moradores (consumidores) se encastelam cada vez mais em seus condomínios que lhes conferem um status. A constituição das chamadas novas centralidades, com a produção de novos centros de negócios, entretenimento, eventos, etc., assim como de novos condomínios residenciais, produz (ou tende a produzir) o que Jacques Lévy identificou nas cidades norteamericanas e denominou "eclipse da rua", que consiste no esvaziamento de pessoas da rua e aumento do movimento de carros. Esta negação da centralidade concreta revela o processo contraditório de produção da cidade. Nesse sentido, segundo Lévy,

Na re-discussão contínua da relação custo/vantagem entre a cidade e as outras escolhas espaciais, certas funções desaparecem do urbano central, outras se reforçam. No conjunto, a indústria não demanda muito a centralidade e prefere trocar seu capital urbano (terrenos no centro da cidade) por vantagens financeiras. Até o presente, apenas uma pequena parcela dos habitantes combinavam a motivação e solvabilidade para reivindicar um desfrute do centro. As evoluções em curso parecem mostrar que uma demanda do centro de tipo moderno (há também uma persistência de um consumo "terceiro-mundista" da cidade) toca preferencialmente as atividades criativas, sejam elas individuais ou coletivas, com intenção econômica (produção de valor de troca), sociológica (dinâmica das relações sociais), psicológica (enriquecimento das relações interpessoais) ou política (cidadania) ${ }^{21}$.

Dessa forma, amplifica-se a contradição presente na vida urbana, pois as centralidades que se impõem no espaço contraditoriamente esvaziam o conteúdo concreto da centralidade, que é aquele da concentração das conquistas da civilização; das possibilidades do encontro da reunião; da cultura; da potencialização das formas de sociabilidade.

Podemos fazer um paralelo do avanço dos novos empreendimentos - novas casas de eventos e shows, concessionárias de automóveis, condomínios residenciais - no espaço de desindustrialização em foco, com a idéia de fronteira urbana elaborada por Neil Smith ${ }^{22}$. Apesar desse autor trabalhar com a realidade dos países desenvolvidos, onde a desindustrialização em áreas urbanas ocorreu muito antes do que ocorreu aqui e os processos de reestruturação urbana tiveram uma dimensão mais generalizada, os processos que ele identifica nos dão elementos para refletirmos sobre a nossa realidade. Ele mostra como as transformações econômicas produzem transformações urbanas profundas; como o espaço urbano ganha maior importância para a constituição do que ele chama de fronteiras econômicas. Na nossa realidade "terceiromundista", podemos afirmar que as contradições promovidas pela concretização das determinações econômicas capitalistas são ainda mais profundas que nos países desenvolvidos. São Paulo representa, em relação ao Brasil como um todo, o elo de ligação com a economia mundial, uma metrópole que vive processos generalizados mundialmente pelo capitalismo. A constituição de novas centralidades na metrópole paulistana reforça essa ligação a mecanismos mais gerais do capitalismo. Algumas áreas da metrópole são tomadas pelos agentes da valorização como fronteiras econômicas, onde as estratégias para essa finalidade atuam fortemente, vislumbrando a reprodução de grandes capitais. A condição de 
A valorização do espaço de desindustrialização da metrópole:

espaços explicitamente voltados à valorização do capital reforça-os na sua condição de mercadoria, inseridos nos mecanismos gerais da produção capitalista do espaço.

Neil Smith mostra como a idéia de fronteira (formulada por Turner em 1893) está ligada à expansão americana em direção ao oeste, significando uma expansão econômica no espaço e representando, ideologicamente, a expansão da civilização sobre a barbárie. Segundo ele, a fronteira urbana que verificamos hoje guarda o sentido de uma expansão econômica espacial e também resgata um sentido ideológico que se reporta à história, quando se trata da renovação de áreas centrais (gentrificação). Analisando a gentrificação como fronteira econômica, ele afirma que,

Hoje, o vínculo entre o desenvolvimento econômico e geográfico persiste, conferindo à imagem de fronteira sua atualidade, mas a forma deste vínculo é bem diferente. No que diz respeito à base espacial, a expansão econômica ocorre hoje não por meio da expansão geográfica absoluta, mas pela diferenciação interna do espaço geográfico (N. Smith, 1982). A produção atual do espaço ou do desenvolvimento geográfico é, portanto, um processo acentuadamente desigual. A gentrificação, a renovação urbana e o mais amplo e complexo processo de reestruturação urbana são todos parte da diferenciação do espaço geográfico na escala urbana; e, embora estes processos tenham sua origem em um período anterior à atual crise econômica mundial, sua função hoje é reservar uma pequena parte do substrato geográfico para um futuro período de expansão (Smith, 1984). E assim como no caso da fronteira original, a mitologia afirma ser a gentrificação um processo liderado por pioneiros e proprietários individuais cujo suor, ousadia e visão estão preparando o caminho para aqueles, entre nós, que são mais temerosos. Mas mesmo que ignoremos a renovação urbana e o redesenvolvimento comercial, administrativo e recreacional que vem ocorrendo, e concentremos-nos apenas na reabilitação residencial, é patente o fato de que, onde quer que os "pioneiros urbanos" se aventurem, os bancos, as incorporadoras, o Estado e outros atores econômicos coletivos geralmente chegam antes ${ }^{23}$.

Nessa sua idéia de gentrificação como fronteira, Smith mostra quem tem o pioneirismo na renovação dos espaços centrais; assim como na fronteira do século XIX em direção ao oeste, os agentes principais deste processo são os grandes grupos econômicos, incluindo aí o Estado. Cria-se uma demanda por centralidade, inclusive lançando mão de uma série de dispositivos culturais que servem de base ideológica para a gentrificação. Fica claro que, para a realização do avanço do capital sobre o espaço, é sempre necessária uma grande e ostensiva carga ideológica. No entanto, este avanço sempre vai entrar em conflito com a irredutibilidade do espaço como dimensão essencial da vida. As estratégias do capital no espaço o negam como espaço da apropriação do corpo, como espaço de realização plena da vida, pois o preenche com mediações econômicas que balizam as normas e garantem a propriedade privada da terra. Segundo Smith, Em primeiro lugar, a fronteira urbana é, antes de mais nada, uma fronteira no sentido econômico. As transformações políticas, sociais e culturais nas 
áreas centrais são amiúde intensas e são certamente importantes no que diz respeito à experiência imediata da vida cotidiana, mas elas estão associadas ao desenvolvimento de uma fronteira econômica. Em segundo lugar, a fronteira urbana é, hoje, apenas uma dentre várias fronteiras existentes, visto que a diferenciação interna do espaço geográfico ocorre em diferentes escalas ${ }^{24}$.

A fronteira urbana evidencia uma problemática espacial, produzindo um espaço em constante transformação, ela própria se configurando como uma transformação necessária do espaço para a reprodução capitalista. Nesse sentido, ainda segundo Smith, enquanto a fronteira do século XIX representou a realização de uma expansão geográfica absoluta como a principal expressão espacial da acumulação de capital, a gentrificação e a renovação urbana representam o exemplo mais desenvolvido da rediferenciação do espaço geográfico com vistas ao mesmo resultado. É possível que, para compreender o presente, o que seja necessário hoje é a substituição de uma falsa história por uma geografia verdadeira ${ }^{25}$.

Nos Estados Unidos, o processo de gentrificação significa a retomada dos espaços centrais pelos poderes econômicos hegemônicos, expulsando para a periferia as classes empobrecidas que habitam estes espaços. No caso específico de nossa pesquisa sobre um espaço de desindustrialização de São Paulo, se trata da constituição de novas centralidades promovidas também por poderosos agentes econômicos, voltadas para a moradia e consumo (lazer, serviços) da classe média alta e alta, em espaços de desindustrialização, colocando em suspenso a permanência da população que aí mora, formada por uma classe média-baixa. Dessa forma, assim como nos Estados Unidos, em nosso estudo de caso o que está em jogo são também processos de renovação, requalificação e gentrificação.

Os fenômenos que observamos na metrópole paulistana nos permitem afirmar que os processos econômicos se espacializam produzindo e reproduzindo contradições. Os processos se realizam numa superposição de escalas - mundial, nacional e local. As determinações econômicas gerais (mundiais) se espacializam em uma determinada realidade nacional e mais proximamente ainda, numa realidade local. O âmbito da ordem próxima revela o aprofundamento das contradições que as lógicas mais gerais produzem. A reestruturação urbana aparece como uma manifestação do movimento geral da economia. Do ponto de vista deste movimento geral,

O que é novo, hoje, é a
intensidade em que esta
reestruturação do espaço se
apresenta como um componente
imediato de uma ampla
reestruturação social e econômica
das economias capitalistas
avançadas. Determinado
ambiente construído expressa
uma organização específica da
produção e reprodução, do
consumo e da circulação, e
conforme esta organização se
modifica, também se modifica a
configuração do ambiente
construído. A cidade dos
pedestres, afirma-se, não é a
cidade do automóvel, mas de
forma ainda mais significativa,
talvez, a cidade do pequeno
artesanato não é a metrópole do
capital multinacional26.

Mesmo nessas áreas em que o poder econômico produz a sua paisagem, o processo não é homogêneo, ele deixa as marcas dos outros usos e relações residuais que ainda se realizam aí. Entram em choque relações de diferentes 
A valorização do espaço de desindustrialização da metrópole:

a produção do espaço como produção da segregação, pp. $105-124$

temporalidades que são simultâneas no espaço da metrópole. Mesmo que muitas vezes o conflito seja escondido por estratagemas ideológicos, ele está presente mesmo nas áreas de aparência mais moderna.

As áreas "deterioradas", objeto da renovação, apresentam aos agentes da valorização, uma oportunidade econômica fundamental, que é o metro quadrado desvalorizado, o que lhes permite maiores ganhos (um rent gap) que em outras áreas mais valorizadas. O crescimento do setor de serviços contribui para a formação de uma demanda para os espaços de desindustrialização.

Já desde as décadas de 1960/70, com mudança no padrão da localização industrial, que passa a privilegiar as áreas periféricas às grandes cidades, áreas centrais se desindustrializavam, propiciando uma grande disponibilidade de terrenos e edifícios para novos usos ${ }^{27}$, possibilitando aos investidores urbanos maiores ganhos com o redesenvolvimento destas áreas centrais. Hoje, áreas industriais outrora periféricas e que se revelam como espaços de desindustrialização, se tornam objeto para a ação dos agentes econômicos da urbanização.

O aumento das atividades do setor terciário, assim como a necessidade do setor imobiliário de se expandir continuamente pelo espaço da cidade, gera um mercado para a gentrificação e a renovação urbana. A proliferação de centros de gestão concentrados, assim como a construção de novos condomínios para as classes média-alta e alta, a instalação de equipamentos de consumo cultural e de entretenimento voltados para o consumo destas classes, além da expansão dos espaços de lazer e de eventos em determinados locais da cidade, contribuem para a afirmação da tendência. Há uma relativa necessidade de concentração das atividades de gestão do capital, aproveitando uma infraestrutura urbana centralizada em determinadas áreas - telecomunicações, transportes, restaurantes, espaços de convenções, hotéis. A localização das atividades de gestão torna-se fundamental, devido à necessidade de agilização de fluxos no espaço.
Com a possibilidade de separação entre as atividades de gestão e as atividades de produção das empresas industriais, através dos avanços técnicos e de transporte, mesmo o capital industrial e a sua gestão tendem à centralização em determinados lugares das metrópoles. As metrópoles, segundo Smith, são produtos da centralização das atividades econômicas mais dinâmicas. Acompanhando a história, essa centralização se dá inicialmente com as atividades industriais, posteriormente, se afirmam as atividades terciárias. Configura-se, nas cidades representativas do capitalismo mundial, um "boom dos escritórios" que refere-se à

contínua centralização espacial dos centros decisórios mais importantes, assim como de uma miríade de serviços auxiliares a estas atividades: assessoria jurídica, serviços de publicidade, hotéis e centros de conferências, editoras, escritórios de arquitetura, bancos e serviços financeiros e muitos outros serviços relacionados aos negócios ${ }^{28}$.

A reestruturação de áreas específicas da metrópole, tornada uma relevante produção econômica, reflete essa necessidade de concentração das atividades terciárias numa economia que se reproduz criticamente. As determinações produzidas no interior dessa economia crítica, produzem as suas configurações espaciais.

Enquanto que na cidade précapitalista foram as necessidades da troca mercantil que ditaram o movimento de centralização espacial, e na cidade industrial capitalista foi a aglomeração do capital produtivo, na cidade capitalista avançada são os ditames financeiros e administrativos que perpetuam a tendência à centralização. Isto 
ajuda a explicar por que certas atividades chamadas de serviços são centralizadas e outras são suburbanizadas, e por que a reestruturação das áreas centrais assume esta forma corporativa/ profissional $^{29}$.

Devemos acrescentar a este encaminhamento, que em São Paulo inicia-se uma tendência de articulação de edifícios de escritórios com condomínios residenciais para um público composto primordialmente por funcionários hierarquicamente superiores das atividades terciárias.

Ainda acompanhando o raciocínio de Neil Smith, ele afirma que

A conclusão lógica da atual reestruturação, que permanece hoje incipiente, seria um centro urbano dominado por funções executivas, financeiras e administrativas de alto nível, habitações para a classe média e classe média alta, e um complexo de hotéis, restaurantes, cinemas, lojas e espaços de cultura oferecendo lazer a esta população. Em resumo, poderíamos esperar a criação de uma área de recreação burguesa, a Manhattanização social da área central para combinar com a Manhattanização arquitetônica que prenunciou a estrutura de empregos em transformação. A provável conseqüência disto é um deslocamento substancial da classe trabalhadora para os subúrbios mais antigos e para a periferia urbana ${ }^{30}$.

O fundamento do processo está no fato de que a reestruturação urbana se assenta na formação de fronteiras urbanas potencializadoras de novos ganhos para as forças econômicas hegemônicas. Tais ganhos resolvem, momentaneamente, crises de acumulação que precisam ser equacionadas pelo sistema econômico. O processo de produção e reprodução do espaço é, portanto, balizado por desvalorizações e revalorizações necessárias e contínuas. As reestruturações, produzindo maiores ganhos em locais desvalorizados, produzem rearranjos espaciais, num processo que estabelece uma estabilidade aparente, mas que, por estar inserido numa economia essencialmente crítica, volta a produzir instabilidade. Assim, a valorização do espaço, sempre almejada pelo processo do capital, necessita, contraditoriamente, da desvalorização para a recriação contínua de novas frentes de expansão para o capital.

\section{Notas}

${ }^{1} \mathrm{O}$ texto é basicamente alguns dos resultados de nossa pesquisa de mestrado intitulada Implicações da desindustrialização e da reestruturação do espaço em um fragmento da metrópole de São Paulo, desenvolvida no âmbito do Programa de Pós-Graduação em Geografia Humana da Faculdade de Filosofia, Letras e Ciências Humanas da Universidade de São Paulo, sob orientação da Profa. Dra. Margarida Maria de Andrade e defendida em 12/07/2007.

2 CARLOS, Ana Fani Alessandri. São Paulo: do capital industrial ao capital financeiro. In: CARLOS, Ana Fani Alessandri e OLIVEIRA, Ariovaldo Umbelino de (orgs.). Geografias de São Paulo - A metrópole do século XXI. São Paulo: Editora Contexto, 2004.

3 Em São Paulo, poderíamos dar o exemplo da região do Brás.

4 LENCIONI, Sandra. Reestruturação urbanoindustrial no Estado de São Paulo: a região da metrópole desconcentrada. In: SANTOS, M.; SOUZA, M. A. A.; SILVEIRA, M. L. (orgs). Território - Globalização e Fragmentação. São Paulo: Hucitec/Anpur, 1994. 
A valorização do espaço de desindustrialização da metrópole:

a produção do espaço como produção da segregação, pp. $105-124$

5 Destacaríamos os serviços finaceiros, concentrando cada vez mais a circulação de capital em São Paulo.

6 Essa idéia de desenvolvimento carrega um explícito sentido ideológico. Na verdade, esse discurso encobre a busca do crescimento econômico.

7 FUSER, Igor. Adeus, Chaminés. In: Revista Exame, 1/12/2000, p.17.

8 Idem, p. 19.

${ }^{9}$ Idem, p.18.

10 Site do Tom Brasil da internet, link de eventos, acesso dia 07/05/2007.

${ }^{11}$ In: Portal Vila Olímpia, site da internet, acesso dia 07/05/2007.

${ }^{12}$ Idem.

${ }^{13}$ Informações obtidas no site da internet do Tom Brasil, acesso dia07/052007.

${ }^{14}$ Informações retiradas do site do Villa Noah Embratel, acesso 08/05/2007.

${ }^{15}$ Idem.

${ }^{16}$ As duas casas de eventos se situam próximas uma da outra (ver mapas 4 e 5 ).

17 Estes "novos produtos imobiliários" são um novo tipo de construção residencial que corresponde a novas "necessidades" que foram criadas. A insegurança na cidade; a necessidade de morar perto do trabalho para evitar trânsito; a possibilidade de usufruir de um grande espaço no próprio condomínio, etc, são elementos com os quais as construtoras jogam para a elaboração dos "novos produtos imobiliários".

18 Para compreendermos melhor o processo de avanço de empreendimentos residenciais neste espaço, entrevistamos dois corretores de dois diferentes empreendimentos.

19 Retirado do mesmo catálogo da citação anterior. XXX representa o nome do novo empreendimento.

20 "O núcleo urbano torna-se assim produto de consumo de uma alta qualidade para estrangeiros, turistas, pessoas vindas da periferia, suburbanos. Ele sobrevive graças a esse duplo papel: lugar de consumo e consumo do lugar. Assim os centros antigos entram mais completamente na troca e no valor de troca não deixando de ser valor de uso em razão de espaços oferecidos às atividades específicas. Eles tornam-se centros de consumo. A resurgência arquitetônica e urbanística do centro comercial não dá senão uma versão enfraquecida e mutilada deste que foi o núcleo da cidade antiga, ao mesmo tempo comercial, religioso, intelectual, político, econômico (produtivo). A noção e a imagem do centro comercial datam de fato da idade média. Ele corresponde à pequena e média cidade medieval. Mas hoje o valor de troca aí domina a tal ponto o uso e o valor de uso, que este é, até certo ponto, suprimido por aquele. Esta noção não tem, portanto, nada de original. A criação que corresponde a nossa época, a suas tendências, a seu horizonte ameaçador não seria o centro de decisões? Este centro reunindo a formação e a informação, as capacidades de organização e de decisões institucionais, aparece como projeto em via de realização de uma centralidade nova, aquela do poder. A este conceito, à pratica que ele denota e justifica, convém dedicar a maior atenção". LEFBVRE, Henri. Le droit à la ville. Paris, Anthropos, 1968, p. 21.

21 LÉVY, Jacques. Centro da Cidade: Todas as Direções. Mimeo.

22 SMITH, Neil. Gentrificação, a fronteira e a reestruturação do espaço urbano. Tradução de Daniel Sanfelice. Edição original: Smith, N. Gentrification, the Frontier, and the Restructuring of Urban Space. In: Readings in Urban Theory edited by Susan S. Fainstein and Scott Campbell (Cambridge, Massachusetts: Blackwell Publishers, 1996). 
${ }^{23}$ Idem, p.4-5.

${ }^{24}$ Idem, p.5-6.

${ }^{25}$ Idem, p.6-7.

${ }^{26}$ Idem, p.8.

27 É preciso ressaltar que a transformação do padrão de localização industrial nos países desenvolvidos ocorre anos após a $2^{a}$ Guerra Mundial. Isso implicou não só o direcionamento das indústrias para a periferia das cidades, mas também a industrialização de algumas áreas nos países do terceiro mundo. Em São Paulo, a industrialização pesada da década de 1950, resultado também dessa desconcentração industrial dos países avançados, ocupou áreas até então periféricas, principalmente no entorno das Avenidas Marginais dos Rios Pinheiros e Tietê e no entorno das rodovias. No entanto, o crescimento acelerado da metrópole incorporou essas áreas como parte da mancha urbana da cidade e hoje algumas delas figuram como áreas bem localizadas para a implantação das novas atividades econômicas que crescem no conjunto das atividades econômicas da metrópole, constituindo novas centralidades.

${ }^{28}$ SMITH, Neil. Op. Cit., p.15.

29 Idem, p.17.

${ }^{30}$ Idem, p.20.

\section{Bibliografia}

CARLOS, Ana Fani Alessandri. São Paulo: do capital industrial ao capital financeiro. In: Ana Fani Alessandri Carlos e Ariovaldo Umbelino de Oliveira (orgs.). Geografias de São Paulo - A metrópole do século XXI. São Paulo: Editora Contexto, 2004.

LEFEBVRE, Henri. Les Ideologies de la Croissance. In: La Survie du Capitalisme. Paris, Anthropos, s/ d.

. Le droit à la ville. Paris: Anthropos, 1968.

. La Ciudad y lo Urbano. El derecho a la ciudad II. Barcelona: Ediciones Península, 1976.

LENCIONI, Sandra. Reestruturação urbanoindustrial no Estado de São Paulo: a região da metrópole desconcentrada. In: Santos, M.; Souza, M. A. A.; Silveira, M. L. (orgs). Território Globalização e Fragmentação. São Paulo: Hucitec/ Anpur, 1994.
LÉVY, Jacques. Centro da Cidade: Todas as Direções. Mimeo, s/d.

MONBEIG, Pierre. Crescimento da Cidade de São Paulo. In: SZMRECSÀNYI, Tamás. História Econômica da Cidade de São Paulo. São Paulo: Editora Globo, 2004.

PETRONE, Pasquale. A Cidade de São Paulo no século XX. In: Revista de História, vol. X, ano VI, são Paulo, 1955.

RAMOS, Aluísio. Desindustrialização na Metrópole Paulistana - O Caso da Água Branca. In: Geousp, n¹0, DG-FFLCH-USP, dezembro de 2001

SMITH, Neil. Gentrificação, a fronteira e a reestruturação do espaço urbano. Tradução de Daniel Sanfelice. Edição original: Smith, N. Gentrification, the Frontier, and the Restructuring of Urban Space. In: Readings in Urban Theory edited by Susan S. Fainstein and Scott Campbell (Cambridge, Massachusetts: Blackwell Publishers, 1996).
Trabalho enviado em junho de 2009. Trabalho aceito em março de 2010. 